\title{
Medio ambiente urbano
}

\author{
Blanca RodrígueZ-Chaves Mimbrero \\ Profesora Contratada Doctora de Derecho Administrativo (Profesora Titular A.) \\ Universidad Autónoma de Madrid
}

\begin{abstract}
Palabras clave: entes locales; medio ambiente; Nuevo Pacto Verde; cambio climático.
\end{abstract}

Keywords: local government; environment; Green New Deal; climate change.

SUMARIO: I. LA LUCHA CONTRA EL CAMBIO CLIMÁTICO EN LA EUROPA POST COVID-19: 1. La UE, motor de una mayor ambición. 2. España: declaración de la emergencia climática y ambiental. 3. La irrupción de la pandemia de covid-19. NextGenerationEU.-II. NORMATIVA, ESTRATEGIAS Y OTRAS DECISIONES EN MATERIA DE MEDIO AMBIENTE (2020): 1. Unión Europea. 2. Derecho interno español: 2.1. Ámbito estatal. 2.2. Ámbito autonómico. 2.3. Ayuntamiento de Madrid: 2.3.1. Líneas de fondos destinados a los municipios. 2.3.2. Calidad del aire y la movilidad.III. JURISPRUDENCIA: 1. Aguas continentales: 1.1. Planes de gestión del riesgo de inundación de las demarcaciones hidrográficas de las Islas Canarias. 2. Contaminación atmosférica: 2.1. Verificadores ambientales. Atribución competencial. 2.2. Obligación de las Comunidades Autónomas de elaborar planes para la protección de la atmósfera. 3. Residuos: 3.1. Competencias municipales en materia de residuos comerciales no peligrosos. 3.2. Valorización de residuos. 3.3. Economía circular. Concepto de residuo y subproducto, relación con los lodos de EDAR. 3.4. Clausura de vertedero. Acondicionamiento. 4. Ruido: 4.1. Requisitos que deben de cumplir las mediciones acústicas. 4.2. Contaminación acústica: medidas que deben adoptar los municipios además de la imposición de sanciones. 5. Contaminación visual. Infraestructuras de telefonía móvil.

\section{LA LUCHA CONTRA EL CAMBIO CLIMÁTICO EN LA EUROPA POST COVID-19}

\section{La UE, motor de una mayor ambición}

Según el informe de la Agencia Europea de Medio Ambiente titulado «El medio ambiente europeo: estado y perspectivas 2020: conocimiento para la transición hacia una Europa sostenible», el estado del medio ambiente en Europa a nivel global ha empeora- 
do desde el último informe en 2015. Si bien Europa ha realizado importantes avances en la eficiencia de los recursos y en la economía circular, las tendencias ponen de manifiesto una ralentización de los progresos en ámbitos como la reducción de las emisiones de gases de efecto invernadero, las emisiones industriales, la generación de residuos, la mejora de la eficiencia energética y la cuota de las energías renovables. De cara al futuro, el ritmo actual de progreso no será suficiente para alcanzar los objetivos de 2030 y 2050 en materia de clima y energía. La protección y conservación de la biodiversidad y la naturaleza europeas sigue siendo la mayor área de actividad de la UE con resultados más desalentadores en relación a los progresos que deberían haberse alcanzado.

Con estos datos el Parlamento Europeo declaró la emergencia climática en noviembre de 2019, determinando que la UE debe garantizar que todas sus propuestas se alinean con el objetivo de limitar el calentamiento a $1,5^{\circ} \mathrm{C}$. Por ello se señala que la UE debe reducir sus emisiones al 55 por 100 en 2030 para lograr la neutralidad en 2050. En esta línea, en plena celebración de la COP 25, el día 11 de diciembre de 2019 la Comisión Europea activó un paquete de medidas para afrontar la emergencia climática a través de su Nuevo Pacto Verde (Green New Deal). El Pacto Verde aborda una decena de áreas, que abarcan desde la neutralidad climática — cero emisiones en 2050- a la sostenibilidad de la Política Agrícola Común, tomando como base la Estrategia «De la granja a la mesa» y la "Estrategia de la UE sobre biodiversidad para 2030».

Sobre el Nuevo Pacto Verde téngase en cuenta:

- D. Fernández de Gatta Sánchez, «El ambicioso Pacto Verde Europeo», Actualidad Jurídica Ambiental, núm. 101, Sección «Comentarios», 12 de mayo de 2020.

- J. Rosa Moreno, «Requerimientos sectoriales del nuevo marco europeo de la energía renovable», Actualidad Jurídica Ambiental, núm. 103, Sección «Artículos doctrinales», 6 de julio de 2020.

- B. LozAno CuTANDA, «Los nuevos proyectos de energías renovables se encuentran con el laberinto jurídico de la evaluación ambiental", Actualidad Jurídica Ambiental, núm. 110, Sección "Comentarios», 8 de marzo de 2021.

\section{España: declaración de la emergencia climática y ambiental}

Con fecha de 21 de enero de 2020, por Acuerdo del Consejo de Ministros se ha declarado la emergencia climática y ambiental. Mediante este acuerdo, el Gobierno se compromete a desarrollar 30 líneas de acción, cinco de ellas en los cien primeros días, para hacer frente a la crisis climática y aprovechar los beneficios sociales y económicos que ofrece la transición ecológica. Entre estas cinco medidas se incluye: «Invertir en un país más seguro y menos vulnerable frente a los impactos y riesgos del cambio climático». En esta línea, se ha aprobado el segundo Plan Nacional de Adaptación al Cambio Climático.

El segundo PNACC 2021-2030 da continuidad al PNACC 2006-2020 y se integra en una amplia batería de estrategias y normas en materia ambiental, como la futura Ley 
de Cambio Climático y Transición Energética, el Plan Nacional Integrado de Energía y Clima o la Estrategia de Transición Justa (estos instrumentos forman parte del Marco Estratégico de Energía y Clima), así como la Estrategia a Largo Plazo para una Economía Moderna, Competitiva y Climáticamente Neutra en 2050. La situación de emergencia climática, declarada por el Gobierno de España el 21 de enero de 2020, ha forzado a que este segundo PNACC sea más ambicioso que su precedente y tome en consideración las indicaciones de la Comisión Europea en la Evaluación respecto a la preparación para la adaptación. Ello ha sido posible gracias a la evaluación del PNACC 2006-2020 y la participación de distintos actores.

La coyuntura climática se aborda en el plano político desde la concepción de dos bloques de medidas. En primer lugar, las destinadas a la prevención y reducción de las emisiones de gases de efecto invernadero son conocidas como medidas de mitigación. En segundo lugar, las medidas de adaptación son aquellas cuyo fin es contrarrestar las consecuencias del cambio climático, es decir, fomentar la recuperación de los ecosistemas, los sistemas sociales y los sistemas económicos cuando acontece una perturbación ambiental. El PNACC es un instrumento de planificación para abordar medidas de adaptación al cambio climático que, asimismo, puede contribuir a la recuperación económica durante y tras la crisis de la covid-19.

Sobre el PNACC vid. M. a PASCUAL NúNEEZ, «El nuevo Plan Nacional de Adaptación al Cambio Climático 2021-2030. El medio ambiente como un vector de la recuperación económica tras la crisis de la covid-19», Actualidad Jurídica Ambiental, núm. 105, Sección «Comentarios», 26 de octubre de 2020.

Estas acciones ponen el énfasis en fortalecer sinergias con las políticas de desarrollo rural, de protección de la biodiversidad y el impulso de las oportunidades para la transición energética, para generar nuevo empleo verde. En este contexto, el Gobierno elaborará la Estrategia de Lucha contra la Desertificación y la Estrategia Nacional Forestal, y la Estrategia frente al Reto Demográfico para facilitar la mejor coordinación entre Administraciones. Del mismo modo está pendiente la tramitación parlamentaria de la Ley de Cambio Climático y Transición Energética que, al igual que la Ley marco de Cambio Climático de la UE (la Comisión debe proponer antes del 31 de mayo de 2023, por medio del procedimiento ordinario de toma de decisiones, una trayectoria europea para alcanzar la neutralidad en carbono antes de 2050), incluirá el objetivo de alcanzar la neutralidad climática a más tardar a mediados de siglo.

La tramitación parlamentaria de la Ley de Cambio Climático y Transición Energética ha sufrido un retraso por una enmienda a la totalidad, por esta circunstancia el Gobierno ha aprobado el Decreto-ley 23/2020, de 23 de junio, por el que se aprueban medidas en materia de energía y en otros ámbitos para la reactivación económica. Estas medidas responden a la urgente finalidad de intentar paliar cuanto antes los efectos de la grave recesión económica causada por la crisis sanitaria de la covid-19 que ha sacudido nuestro país y el mundo entero súbitamente. Conjugando ambos contextos, a saber, la emergencia climática y la crisis sanitaria y económica, el Gobierno plantea la política 
energética como una gran protagonista y motor, la denominada "palanca verde» de la recuperación económica y de empleo, a la vez que intenta cumplir con los ineludibles compromisos internacionales. Esta normativa llega ya con mucho retraso, téngase en cuenta que muchas Comunidades Autónomas ya tienen su propia Ley de Cambio Climático: Cataluña con la Ley 16/2017, de 1 de agosto, desarrollada en materia de energías renovables mediante el Decreto-ley 16/2019, de 26 de noviembre; Andalucía, con la Ley 8/2018, de 8 de octubre, y Baleares con la Ley 10/2019, de 22 de febrero; así como otras, como País Vasco y Comunidad Valenciana, que se encuentran tramitando su Borrador de Ley de Cambio Climático y Transición Energética.

Sobre esta materia téngase en cuenta: M. ${ }^{a}$ PASCUAL NúÑEZ, «La evaluación ambiental estratégica del plan nacional integrado de energía y clima 2021-2030 y la integración de los aspectos ambientales en la planificación pública para la próxima década», Actualidad Jurídica Ambiental, núm. 109, Sección "Comentarios», 15 de febrero de 2021, y M.a PASCUAL NúNEZZ, "La tramitación de la Ley de Cambio Climático y Transición energética en tiempos de la covid-19", Actualidad Jurídica Ambiental, núm. 101, Sección «Comentario legislativo», 5 de mayo de 2020.

\section{La irrupción de la pandemia de covid-19. NextGenerationEU}

La covid-19 representa un ejemplo de los vínculos entre la degradación medioambiental general y sus repercusiones concretas en nuestra salud y bienestar. En el año 2020 se han publicado dos importantes informes, «Perspectiva Mundial sobre la Diversidad Biológica 5», a cargo del Convenio sobre la Diversidad Biológica, y el «Informe Planeta Vivo 2020», de WWF. En ambos se hace hincapié en la alarmante velocidad del declive de la diversidad biológica y se urge a tomar medidas contundentes e inmediatas a escala mundial. En Europa se observan las mismas tendencias preocupantes, que afectan a la resiliencia, la productividad y la capacidad de protegernos que tiene la naturaleza. La pandemia de covid-19 ha alterado radicalmente las expectativas energéticas, tanto económicas como geopolíticas. La gobernanza climática también se ha visto afectada en un año clave para elevar la ambición. La irrupción del coronavirus ha transformado por completo el escenario global, y la energía y el clima no son una excepción. El panorama a corto plazo ha mutado al ritmo del virus; no obstante, los retos de la transición energética y la lucha contra el cambio climático permanecen inalterables. Mejorar la resiliencia de la naturaleza a nivel mundial mediante la protección, la conservación y la restauración de los espacios naturales y la evolución a un sistema alimentario sostenible no solo reducirá probablemente los riesgos asociados a las enfermedades zoonóticas, sino que también garantizará nuestro bienestar a largo plazo.

Con todo, parece que se mantiene la transición energética en las agendas políticas siguiendo la senda establecida en el Pacto Verde Europeo. Los propósitos a largo plazo de las políticas europeas se encuentran plasmados en el Pacto Verde Europeo, así como en sus estrategias y sus planes de acción. En este sentido, el 14 de octubre de 2020 se 
aprobó la Propuesta de Decisión relativa al Programa General de Acción de la Unión en materia de Medio Ambiente hasta 2030 [COM (2020) 652 final, Bruselas, 14 de octubre de 2020]. El VIII Programa Ambiental complementará las iniciativas adoptadas en el marco del Pacto Verde Europeo, principalmente el Plan de Acción para la Economía Circular, la denominada «Ley Europea del Clima», que consagra el objetivo de neutralidad climática para 2050, la Estrategia sobre Biodiversidad para 2030 o la iniciativa "De la granja a la mesa». En lo que se refiere al ámbito local, el VIII PAM debe desarrollar un marco integrado para dotar a las entidades locales y regionales de los instrumentos adecuados en consonancia con la estrategia de recuperación ecológica tras la covid-19.

Sobre el VIII PAM vid. D. Fernández de Gatta Sánchez, «El Octavo Programa Ambiental de la Unión Europea: la propuesta de decisión de 14 de octubre de 2020 (1)», La Ley Unión Europea, núm. 87, 2020.

En el discurso sobre el Estado de la Unión de la presidenta de la Comisión Europea, Úrsula von der Leyen, no solo ratificó el compromiso de Europa con dichos objetivos, sino que incluso elevó las ambiciones medioambientales. Estas se han de lograr mediante una transición justa, abordando las desigualdades y la justicia social de la mano de los objetivos climáticos.

En esta línea, el Plan de recuperación para Europa, concebido para contribuir a la reparación de los daños económicos y sociales provocados por la pandemia de coronavirus, e iniciar la recuperación europea y preservar y crear empleo, incluye un nuevo instrumento de recuperación, NextGenerationEU, que contiene un refuerzo en el proceso de recuperación y ejecución del Pacto Verde Europeo.

El 7 de octubre de 2020, el Gobierno español presentó el «Plan Nacional de Recuperación, Transformación y Resiliencia». Este plan contiene claramente una agenda verde; al menos el 37 por 100 de los recursos (con la inversión de 72.000 millones de euros de fondos europeos) se destinarán a la descarbonización y la transición ecológica, reforzados por una transformación digital. Se pretende hacer España más resiliente, modernizando la industria y promoviendo una recuperación económica verde (y azul), pero preservando nuestra naturaleza y biodiversidad, que nos hace en este sector en una potencia de primera línea europea. En este punto el Gobierno tiene como línea de trabajo: la restauración ecológica, la naturaleza, los bosques, sin olvidar la biodiversidad marina y un plan de recuperación fluvial y de acuíferos. Estas iniciativas políticas pueden tener un gran potencial para la mejora de la España rural.

El «Plan Nacional de Recuperación, Transformación y Resiliencia» se estructura en torno a diez políticas tractoras que van a incidir directamente en aquellos sectores productivos con mayor capacidad de transformación de nuestro tejido económico y social.

Los próximos meses se revelarán decisivos para definir los planes de recuperación e inversión. Hemos de velar por que cada paso que demos en este sentido nos acerque a la sostenibilidad. 
Sobre las cuestiones tratadas resulta de mucho interés consultar:

- E. Martín Pascual, «El Pacto Verde Europeo: ¿posible salida verde de la crisis de la covid-19?», Revista General de Derecho Europeo, núm. 51, 2020.

- Í. Del Guayo Castiella, "Concepto, contenidos y principios del derecho de la energía", Revista de Administración Pública (CEPC), núm. 212, 2020, pp. 309-345.

- J. Rosa Moreno y G. Valencia Martín (dirs.), La transformación renovable del modelo energético, Cizur Menor (Navarra), Aranzadi, 2020.

\section{NORMATIVA, ESTRATEGIAS Y OTRAS DECISIONES EN MATERIA DE MEDIO AMBIENTE (2020)}

\section{Unión Europea}

A nivel europeo, destaca la Propuesta de Reglamento del Parlamento Europeo y del Consejo por el que se establece el marco para lograr la neutralidad climática y se modifica el Reglamento (UE) 2018/1999 ("Ley Europea del Clima») [COM (2020) 80 final, de 4 de marzo de 2020].

El objetivo de la propuesta es vinculante y consiste en alcanzar la neutralidad climática en la Unión de aquí a 2050, con la intención de, al tiempo, cumplir con otros complementarios como la reducción de la temperatura comprometida en París. Para lograrlo, se establece un marco dirigido a garantizar la reducción progresiva e irreversible de las emisiones de gases de efecto invernadero antropogénicas y el incremento de las absorciones por sumideros naturales o de otro tipo en la Unión. Estas emisiones a las que se refiere la propuesta son las recogidas actualmente por el Reglamento (UE) 2018/1999 sobre gobernanza de la Unión de la Energía y Acción por el Clima. Un Reglamento que, junto a las Directivas 2018/2001 relativa al fomento del uso de energía procedente de fuentes renovables y 2018/2002 de eficiencia energética, representó uno de los hitos más recientes de la protección del medio ambiente en Europa, actualizando por completo la política energética de la Unión bajo una perspectiva ambiental.

La propuesta de Reglamento propone un enfoque adaptativo con el que estructura el alcance de la neutralidad en etapas o tramos, a través de los que se podrán adaptar tanto los objetivos a corto y medio plazo, como las medidas a tomar a nivel global y estatal (art. 2 de la propuesta):

1. Objetivo general: 2050: «Las emisiones y absorciones de gases de efecto invernadero reguladas en la legislación de la Unión estarán equilibradas a más tardar en 2050, por lo que en esa fecha las emisiones netas deben haberse reducido a cero». En este tiempo, «las instituciones pertinentes de la Unión y los Estados miembros adoptarán las medidas necesarias a nivel de la Unión y nacional, respectivamente, para permitir la consecución colectiva del objetivo de neutralidad climática, teniendo en cuenta la importancia de promover la equidad y la solidaridad entre los Estados miembros». 
2. Primera etapa: septiembre de 2020: a más tardar en septiembre de 2020, la Comisión revisará el objetivo de la Unión para 2030 en materia de clima recogido en el Reglamento (UE) 2018/1999 «y estudiará opciones en relación con un nuevo objetivo para 2030 de una reducción de emisiones de entre el 50 y el 55 por 100 en comparación con los niveles de 1990. Si la Comisión considera necesario modificar ese objetivo, presentará propuestas al Parlamento Europeo y al Consejo, según proceda».

3. ${ }^{\circ}$ Segunda etapa: 30 de junio de 2021: «A más tardar el 30 de junio de 2021, la Comisión evaluará cómo habría que modificar la legislación de la Unión por la que se aplica el objetivo de la Unión para 2030 para que se pueda lograr una reducción de las emisiones del 50 al 55 por 100 en comparación con 1990 y alcanzar el objetivo de neutralidad climática», para lo que «estudiará la posibilidad de adoptar las medidas necesarias, incluso propuestas legislativas, de conformidad con los Tratados».

4. ${ }^{\circ}$ Tercera etapa: la etapa intermedia clave: año 2030: el cumplimiento de objetivo intermedio propuesto para 2030 marcará la hoja de ruta a seguir hasta el logro de la neutralidad en 2050. Conforme a los resultados que se vayan obteniendo, la Comisión estará facultada para adoptar actos delegados a fin de establecer una trayectoria común para toda la Unión. Para elaborar esta trayectoria la Comisión deberá considerar (art. 3 de la propuesta) lo siguiente: «a) la rentabilidad y la eficiencia económica; $b$ ) la competitividad de la economía de la Unión; c) la mejor tecnología disponible; $d$ ) la eficiencia energética, la asequibilidad de la energía y la seguridad de abastecimiento; $e$ ) la equidad y solidaridad entre los Estados miembros y dentro de cada uno de ellos; $f$ ) la necesidad de garantizar la eficacia ambiental y los avances a lo largo del tiempo; $g$ ) las necesidades y oportunidades en materia de inversión; $h$ ) la necesidad de garantizar una transición justa y socialmente equitativa; i) la evolución y los esfuerzos internacionales para alcanzar los objetivos a largo plazo del Acuerdo de París y el objetivo último de la Convención Marco de las Naciones Unidas sobre el Cambio Climático, y j) la mejor y más reciente información científica, incluidos los últimos informes del IPCC».

El último gran punto que destacar de la propuesta está en la obligación de adaptación al cambio climático (art. 4). Para cumplir con esta adaptación, la Unión y los Estados deberán garantizar «un progreso continuo en el aumento de la capacidad de adaptación, el fortalecimiento de la resiliencia y la reducción de la vulnerabilidad al cambio climático». Además, los Estados miembros deberán desarrollar y aplicar «estrategias y planes de adaptación que incluyan marcos globales de gestión de riesgos, basados en bases de referencia sólidas en materia de clima y vulnerabilidad y en la evaluación de los progresos realizados».

\section{Derecho interno español}

\section{1. Ámbito estatal}

A nivel estatal, destacan los siguientes instrumentos:

- Estrategia Nacional de Infraestructura Verde y de la Conectividad y Restauración Ecológicas, aprobada por el Consejo de Ministros el 27 de octubre de 2020. 
- El Plan Nacional de Adaptación al Cambio Climático (PNACC) 2021-2030, aprobado por el Consejo de Ministros el 22 de septiembre de 2020.

- Estrategia a Largo Plazo para una Economía Moderna, Competitiva y Climáticamente Neutra en 2050, aprobada por el Consejo de Ministros el 3 de noviembre de 2020.

- Resolución de 16 de noviembre de 2020, de la Dirección General de Biodiversidad, Bosques y Desertificación, por la que se integran en la Red de Áreas Marinas Protegidas de España ocho zonas especiales de conservación marinas de la Región Biogeográfica Mediterránea de la Red Natura 2000 y el Área Marina Protegida el Corredor de migración de cetáceos del Mediterráneo.

- Estrategia Nacional para la Conservación de los Polinizadores, aprobada por la Conferencia Sectorial de Medio Ambiente el 21 de septiembre de 2020.

- Real Decreto-ley 36/2020, de 30 de diciembre, por el que se aprueban medidas urgentes para la modernización de la Administración pública y para la ejecución del Plan de Recuperación, Transformación y Resiliencia.

- Real Decreto-ley 23/2020, de 23 de junio, por el que se aprueban medidas en materia de energía y en otros ámbitos para la reactivación económica. Sobre el mismo, vid. C. FernándeZ-Espinar MuÑoz, "Comentario al Real Decreto-ley 23/2020, de 23 de junio, por el que se aprueban medidas en materia de energía y en otros ámbitos para la reactivación económica», Actualidad Jurídica Ambiental, núm. 103, Sección "Comentarios de legislación", 27 de julio de 2020.

- Real Decreto 429/2020, de 3 de marzo, por el que se aprueba el Reglamento sobre acceso a los recursos fitogenéticos para la agricultura y la alimentación y a los cultivados para utilización con otros fines, y se modifican diversos reales decretos en materia de productos vegetales.

- Real Decreto 553/2020, de 2 de junio, por el que se regula el traslado de residuos en el interior del territorio del Estado. Sobre el mismo, vid. B. LozAno CuTANDa y P. PoveDA, «Real Decreto 553/2020, por el que se regula el traslado de residuos en el interior de España», Actualidad Jurídica Ambiental, núm. 105, Sección «Comentarios de legislación», 7 de octubre de 2020.

- Real Decreto 646/202, de 7 de julio, por el que se regula la Eliminación de Residuos mediante Depósito en Vertedero. Sobre el mismo, vid. B. Lozano CuTANDa y P. PoveDA, «Real Decreto 646/2020 sobre la eliminación de residuos mediante depósito en vertederos: principales novedades», Actualidad Jurídica Ambiental, núm. 108, Sección "Comentarios legislativos", 18 de enero de 2021.

- Real Decreto 1089/2020, de 9 de diciembre, por el que se desarrollan aspectos relativos al ajuste de la asignación gratuita de derechos de emisión de gases de efecto invernadero en el periodo 2021-2030.

\section{2. Ámbito autonómico}

A nivel autonómico, se han producido en la materia las siguientes novedades: 


\section{Andalucía}

- Acuerdo de 22 de septiembre de 2020, del Consejo de Gobierno, por el que se aprueba la Estrategia Andaluza de Calidad del Aire.

- Decreto-ley 31/2020, de 1 de diciembre, de medidas extraordinarias y urgentes en materia de evaluación ambiental estratégica de determinados instrumentos de planeamiento urbanístico y para impulsar la realización de proyectos de absorción de emisiones en Andalucía, así como de apoyo económico a las entidades prestadoras de los servicios de atención residencial, centro de día y de noche, y centro de día con terapia ocupacional para personas en situación de dependencia, como consecuencia de la situación ocasionada por el coronavirus (covid-19).

\section{Baleares}

- Ley 2/2020, de 15 de octubre, de medidas urgentes y extraordinarias para el impulso de la actividad económica y la simplificación administrativa en el ámbito de las administraciones públicas de las Illes Balears para paliar los efectos de la crisis ocasionada por la covid-19.

\section{Castilla-La Mancha}

- Ley 2/2020, de 7 de febrero, de Evaluación Ambiental de Castilla-La Mancha.

\section{Castilla y León}

- Acuerdo 28/2020, de 11 de junio, de la Junta de Castilla y León, por el que se aprueba la Estrategia para la mejora de la calidad del aire en Castilla y León, 2020-2030.

- Acuerdo 26/2020, de 4 de junio, de la Junta de Castilla y León, por el que se aprueban medidas contra el cambio climático en el ámbito de la Comunidad de Castilla y León.

\section{Cataluña}

- Decreto-ley 18/2020, de 12 de mayo, de medidas urgentes en materia de urbanismo, fianzas y ambiental.

- Pacto nacional por una movilidad segura y sostenible para el periodo 20212030, aprobado por Acuerdo GOV/3/2021, de 19 de enero.

- Ley 7/2020, de 2 de julio, de la Agencia de la Naturaleza de Cataluña.

- Ley 8/2020, de 30 de julio, de protección y ordenación del litoral.

E. Morelle Hungría, «La Ley 8/2020, de 30 de julio, de protección y ordenación del litoral de Cataluña. La necesaria visión holística en la planificación ambiental», $R e-$ vista General de Derecho Administrativo, núm. 55, octubre de 2020.

«Nueva ley de protección y ordenación del litoral de Cataluña, Práctica Urbanística», Revista Mensual de Urbanismo, núm. 166, 2020. 
- Decreto-ley 33/2020, de 30 de septiembre, de medidas urgentes en el ámbito del impuesto sobre las emisiones de dióxido de carbono de los vehículos de tracción mecánica y del impuesto sobre las estancias en establecimientos turísticos, y en el ámbito presupuestario y administrativo.

\section{Extremadura}

- Decreto-ley 12/2020, de 19 de junio, de medidas extraordinarias y urgentes para la reactivación de la actividad económica y social en la Comunidad Autónoma de Extremadura en el proceso hacia la «Nueva Normalidad».

\section{Galicia}

- Decreto 73/2020, de 24 de abril, por el que se regulan los aprovechamientos madereros y leñosos, de corcho, de pastos, micológicos y de resinas en montes o terrenos forestales de gestión privada en la Comunidad Autónoma de Galicia.

\section{Madrid}

- Plan de Actuación sobre Humedales Catalogados (BOCM núm. 93, de 18 de abril de 2020).

\section{Murcia}

— Ley 3/2020, de 27 de julio, de recuperación y protección del Mar Menor.

«Murcia limita el uso de fertilizantes en el entorno del Mar Menor, Práctica Urbanística», Revista mensual de urbanismo, núm. 166, 2020.

- Ley 5/2020, de 3 de agosto, de mitigación del impacto socioeconómico de la covid-19 en el área de medio ambiente.

\section{Navarra}

- Ley Foral 17/2020, de 16 de diciembre, reguladora de las Actividades con Incidencia Ambiental.

- Decreto-ley foral 6/2020, de 17 de junio, por el que se aprueban medidas urgentes para responder al impacto generado por la crisis sanitaria del coronavirus (covid-19). País Vasco

- Decreto 254/2020, de 10 de noviembre, sobre Sostenibilidad Energética de la Comunidad Autónoma Vasca.

\section{Valencia}

- Decreto-ley 14/2020, de 7 de agosto, del Consell, de medidas para acelerar la implantación de instalaciones para el aprovechamiento de las energías renovables por la emergencia climática y la necesidad de la urgente reactivación económica. 
Sobre normativa autonómica, téngase muy en cuenta R. J. SANTAMARÍA ARINAS, "Innovación normativa para la economía circular en leyes autonómicas», Revista General de Derecho Administrativo, núm. 55, octubre de 2020.

\subsection{Ayuntamiento de Madrid}

\subsubsection{Líneas de fondos destinados a los municipios}

El 27 de octubre de 2020, el Consejo de Ministros aprobó el reparto territorial de cerca de 20 millones de euros para mejorar la gestión de residuos, la adaptación al cambio climático y la protección de la biodiversidad. En concreto, se distribuirán 9 millones para actuaciones en la adaptación al cambio climático en el espacio urbano y periurbano, 5,8 millones para mejorar la gestión de residuos y reducir su contribución a las emisiones de gases de efecto invernadero y otros cinco millones en la protección del espacio natural y la conservación de especies. Algunas de las medidas que se llevarán a cabo con este presupuesto tendrán como objetivo la integración del cambio climático e infraestructura verde en la planificación y gestión urbanística, la adaptación de edificios públicos para prevenir el exceso de calor y mejorar la eficiencia energética o el aumento de la biodiversidad urbana y la mejora de los hábitats dentro de estas zonas.

También, en esta misma línea de actuación se recogen las ayudas al diseño e implantación de Zonas de Bajas Emisiones con el fin de mejorar la calidad del aire y mitigar las emisiones de gases de efecto invernadero. En este caso, los beneficiarios serán municipios entre 50.000 y 100.000 habitantes.

La territorialización de los fondos aprobados se ha llevado a cabo en función de proyecciones climáticas — concretamente, de las necesidades de refrigeración en cada territorio-, del número de municipios menores de 100.000 habitantes y de la población en municipios menores de 100.000 habitantes, estableciéndose un máximo de 1 millón de euros y un mínimo de 100.000 para cada administración autonómica.

Del mismo modo, también el Consejo de Ministros ha aprobado la distribución de 5,87 millones de euros procedentes del PIMA Residuos y de las líneas presupuestas asignadas a la política de residuos con el objetivo de promover actuaciones que permitan mejorar la gestión de los residuos para avanzar en la consecución de los objetivos nacionales y comunitarios en esta materia y reducir las emisiones de gases de efecto invernadero asociadas al sector. Entre las actuaciones para implementar la política de residuos que se financian, se incluyen proyectos de compostaje doméstico y comunitario y para la utilización eficiente de biogás, y en el marco de la línea del PIMA Residuos se financian actuaciones de recogida separada de biorresiduos, instalaciones de compostaje y de recogida de aceite de cocina usado para producción de biodiésel.

Relacionado con la movilidad, por Real Decreto 569/2020, de 16 de junio, se ha aprobado el Programa de incentivos a la movilidad eficiente y sostenible (MOVES II) y 
se acuerda la concesión directa de las ayudas de este programa a las Comunidades Autónomas y a las ciudades de Ceuta y Melilla. Las ayudas reguladas por este Real Decreto serán cofinanciadas por el Fondo Europeo de Desarrollo Regional (FEDER) dentro del Programa Operativo Plurirregional de España 2014-2020.

La primera edición del Programa MOVES cerró su vigencia el 31 de diciembre de 2019, con un grado de compromiso de fondos del 82,5 por 100 y un presupuesto comprometido de cerca de 37,2 millones de euros para dar respuesta a un total de 6.182 solicitudes. Referida a la primera edición del Programa MOVES, la STS 1933/2020, de 29 de junio, analiza el Real Decreto 72/2019, de 15 de febrero, por el que se regula el programa de incentivos a la movilidad eficiente y sostenible (Programa MOVES) y pone de relieve la necesidad de lograr una mejor ejecución de los fondos destinados al Programa MOVES para contribuir a los objetivos de descarbonización, que obligan a priorizar las ayudas hacia los combustibles que más contribuyen a este objetivo prioritario, sopesando la madurez de la tecnología y la competitividad de los precios.

La segunda edición, denominada MOVES II, modifica ciertos requisitos de la primera a fin de conseguir una mejor ejecución de los fondos y una contribución a los objetivos de descarbonización del sector transporte de acuerdo con lo establecido en el Plan Nacional Integrado de Energía y Clima 2021-2030. Las principales modificaciones se centran en ampliar las actuaciones elegibles para apoyar a los ayuntamientos en su adaptación a la necesidades de movilidad tras la pandemia, incluir el achatarramiento de un vehículo de más de siete años como opcional, incremento del precio límite de un vehículo turismo para ser elegible, ampliar el presupuesto máximo que se puede dedicar a vehículos pesados de gas, ante la demanda generada, y dar mayor flexibilidad a las Comunidades Autónomas y ciudades de Ceuta y Melilla en su gestión.

Esta edición tendrá en cuenta medidas que permitan afrontar los retos que la nueva situación post covid-19 plantea a nivel de movilidad en los núcleos urbanos, principalmente en los desplazamientos al centro de trabajo o estudios, cumpliendo además los objetivos de sostenibilidad, los criterios de eficiencia energética, el impulso del uso de energías alternativas y la hoja de ruta hacia la descarbonización.

\subsubsection{Calidad del aire y la movilidad}

Uno de los ámbitos con la sostenibilidad que más afecta a los ciudadanos es el de la calidad del aire y la movilidad. En este ámbito, en septiembre de 2019 se presentó por el Ayuntamiento de Madrid la Estrategia «Madrid 360» dirigida a cumplir con los objetivos de calidad del aire de la Unión Europea establecidos en la Directiva 2008/50/ CE, del Parlamento Europeo y del Consejo, de 21 de mayo.

Las principales medidas que recoge «Madrid 360» son:

- Creación de la Línea Cero, la primera línea de autobús de la EMT gratuita que vertebrará el distrito Centro en sentido norte-sur y este-oeste. 
- Los vehículos A que no sean de residentes de Madrid no podrán circular por el interior de la M-30 a partir del 1 de enero de 2022.

- No habrá calderas de carbón en la ciudad a partir del 1 de enero de 2022 y se pretende eliminar el 50 por 100 de las que funcionan por gasóleo en ocho años. Se destinarán 50 millones de euros en ayudas para alcanzar estos objetivos hasta 2023. Se permitirá el acceso y circulación de los vehículos $\mathrm{C}$ de alta ocupación en el distrito Centro

- Esta estrategia está alineada con los Objetivos de Desarrollo Sostenible de la Agenda 2030 de Naciones Unidas.

- Peatonalización de Sol y su entorno con el objetivo de convertirla en una auténtica zona cero de emisiones. Se incluirán nuevas peatonalizaciones en otras vías y en otros cascos históricos de los distritos previo análisis.

- Nuevo Bosque Metropolitano. Se crearán 600 hectáreas de corona forestal, con la plantación de 100.000 árboles nuevos, así como ecoductos (puentes verdes) por encima de la R-3 o la A-3. Supondrá la absorción de 170.000 toneladas de $\mathrm{CO}_{2}$ cuando el bosque alcance la madurez. El presupuesto estimado para la primera fase es de 20 millones de euros hasta 2023.

- Apuesta por la bicicleta, la moto y otros transportes alternativos.

- Construcción de 15.000 plazas de aparcamiento: 10.000 en 14 aparcamientos disuasorios y 5.000 plazas de rotación y residentes.

Las medidas de «Madrid 360» han sido evaluadas por la UPM confirmándose que reducirán 1.563 toneladas de óxidos de nitrógeno al año.

Los cálculos de la Universidad Politécnica de Madrid, que evalúan las actuaciones hasta 2023, establecen que la nueva estrategia tiene un impacto de reducción del 11,3 por 100 para los óxidos de nitrógeno (NOx) emitidos a la atmósfera.

Las medidas que más incidencia tienen en la mejora de la calidad del aire son las que contemplan las restricciones a la circulación de los vehículos A y la renovación del parque de vehículos.

Han quedado fuera de la modelización la ampliación de carriles bus en nuevos desarrollos, el plan de optimización de Valdemingómez, la línea perimetral de Centro o el uso de aparcamientos de la EMT en Centro como puntos de distribución de mercancías.

Entre las medidas modelizadas, hay algunas que son totalmente nuevas como, por ejemplo, la puesta en marcha de las líneas cero o el SER dinámico y otras que son más inminentes y van más allá de las planteadas en el Plan A como las restricciones a la circulación de los vehículos A o la renovación de la flota de la EMT, entre otras. Hay que tener en cuenta, además, que la evaluación previa de la UPM estaba cuantificada para el periodo 2012-2020 (ocho años) y «Madrid 360» está analizada para el periodo 2018 y 2023 (cinco años).

La Estrategia «Madrid 360» se ha configurado como herramienta clave para establecer actuaciones estructurales que van más allá de las aprobadas en el Plan A, el último 
plan de calidad del aire y cambio climático que ratificó el Ayuntamiento de Madrid en septiembre de 2012.

La Estrategia «Madrid 360» entrará en vigor con la nueva Ordenanza de Calidad del Aire y Sostenibilidad, que ha sido aprobada por el Pleno del Ayuntamiento de Madrid, el 30 de marzo de 2021. El nuevo texto municipal se fundamenta en cuatro objetivos: mejora de la calidad del aire, reducción de la contaminación, impulso a la eficiencia energética y fomento de la electromovilidad. Con respecto al borrador de ordenanza, adelanta un año la obligación de que todos los edificios no residenciales incluyan infraestructuras de recarga eléctrica a partir de las 20 plazas de aparcamiento. Regula nuevos aspectos como la prohibición del funcionamiento de calderas de carbón desde el 1 de enero de 2022 o la obligación de que los vehículos más contaminantes en circulación pasen una ITV puntual cuando así lo requiera un agente de la autoridad. Establece el consumo eléctrico "casi nulo" para las nuevas edificaciones. Y, por primera vez, se legisla sobre la celebración de grandes eventos en la ciudad para minimizar su impacto ambiental y que sean sostenibles. Esta nueva ordenanza se fundamenta en cuatro objetivos prioritarios para el Gobierno municipal: la mejora de la calidad del aire, la reducción de la contaminación, el impulso a la eficiencia energética y el fomento de la electromovilidad.

En esta materia hay que tener en cuenta que por STSJ de Madrid 8150/2020, de 27 de julio, se ha declarado la nulidad del art. 23 y de la DT 3. a de la Ordenanza de Movilidad Sostenible, aprobada por Acuerdo del Pleno del Ayuntamiento de Madrid, de 5 de octubre de 2018, porque la memoria económica que acompañó a la Ordenanza de Movilidad Sostenible no reflejó los costes económicos que implicaba la puesta en marcha, implantación y desarrollo de "Madrid Central», incumpliendo claramente con su objetivo principal de explicar de forma detallada y clara los gastos que conllevaba la implantación de las medidas en esta zona desde un punto de vista económico. Se debe señalar que, en esta misma línea, la Sala se ha pronunciado en otra sentencia de igual fecha.

El decisivo papel de las entidades locales en la mitigación y adaptación ante el Cambio Climático a lo largo del año 2020 ha estado presente en:

Las» Jornadas Internacionales sobre entes locales y transición energética», celebradas en la Universidad de Málaga, el 23 de enero de 2020.

Y en los siguientes trabajos publicados en 2020:

- E. ARANA GarCía, El control de la colaboración privada en la gestión de los servicios urbanos del agua. Hacia un pacto social por la gestión del agua, Valencia, Tirant lo Blanch, 2020.

- P. de la Cruz López, «Las Smart Cities: fenómeno y retos», en E. OrTega Burgos (dir.), Mercados regulados 2020, Valencia, Tirant lo Blanch, 2020, pp. 385-402.

- J. A. España PéREZ, "La problemática jurídica de la protección de datos en la "Smart Mobillty". Especial referencia al reglamento 2016/679", Revista Española de Derecho Administrativo, núm. 207, julio-septiembre de 2020, pp. 299-338. 
- G. Halegoua, Smart Cities, Cambridge (Estados Unidos), The Mit Press, 2020.

- «La Nueva Agenda Urbana: Municipio y Objetivos de Desarrollo Sostenible», Revista de Estudios Locales, Cunal, núm. extra 232, 2020, pp. 1-397.

- Á. Lara García y L. De Moral ItUarte, «El derecho humano al agua en España en el contexto europeo (2010-2020). Implicaciones para las políticas y los modelos de gestión del ciclo urbano», Relaciones Internacionales, núm. 45, octubre de 2020, pp. 305-326.

- F. Lara González, «Movilidad sostenible», en E. Ortega Burgos (dir.), Mercados regulados 2020, Valencia, Tirant lo Blanch, 2020, pp. 783-501.

- I. ORTega Moreno, «Smart City: la revolución digital y el papel de las ciudades como garante de los derechos de los ciudadanos», en Á. Valencia Saiz (dir.); G. SÁnChez-Archidona Hidalgo y A. M. ${ }^{a}$ Pastor García (coords.), Desafíos actuales del derecho: aportaciones presentadas al II Congreso Nacional de jóvenes investigadores en Ciencias Jurídicas, Málaga, EUMED, 2020, pp. 495-509.

\section{JURISPRUDENCIA}

\section{Aguas continentales}

\subsection{Planes de gestión del riesgo de inundación de las demarcaciones hidrográficas de las Islas Canarias}

La STJUE de 2 de abril de 2020, asunto C-384/19, ha determinado que España ha incumplido la Directiva 2007/60, relativa a la evaluación y gestión de los riesgos de inundación, por no haber adoptado tempestivamente los planes de gestión del riesgo de inundación de las demarcaciones hidrográficas de las Islas Canarias. Se trata del primer caso enjuiciado por el TJUE sobre el cumplimiento de la Directiva de Inundaciones de 2007 por los Estados miembros.

\section{Contaminación atmosférica}

\subsection{Verificadores ambientales. Atribución competencial}

La STS 3871/2020, de 17 de noviembre, resuelve el recurso de casación interpuesto por la Generalitat de Catalunya contra la sentencia dictada por la Sala de lo Contencioso-Administrativo de la Audiencia Nacional (Sección 7.a), de 14 de junio de 2019, que desestimó el recurso interpuesto contra el art. 4.2, párrafo 2. ${ }^{\circ}$, de la Orden PARA/321/2017, de 7 de abril, por la que se regulan los procedimientos de determinación de las emisiones de los contaminantes atmosféricos SO2, Nox, partículas y CO procedentes de grandes instalaciones de combustión, el control de los instrumentos de medida y el tratamiento y remisión de la información relativa a dichas emisiones. 
La cuestión fundamental que centra la controversia es determinar si la competencia para acreditar los laboratorios que deban realizar los ensayos NGC2 de calibración de los sistemas automáticos de medida (SAM) debe ser reservada en exclusiva a la Entidad Nacional de Acreditación (ENAC), bien por sí misma, bien a través de los organismos con los que haya suscrito acuerdo de reconocimiento, como hace la Orden impugnada, o pueden desarrollar esta función otros organismos designados a tal efecto por la Comunidad Autónoma de Cataluña. En este caso el Alto Tribunal determina que la función de calibración de los aparatos de medición de las emisiones no es una acción directamente vinculada al control de la contaminación atmosférica, sino a la comprobación del correcto funcionamiento de un aparato medidor en el lugar de su ubicación. En consecuencia, concluye que la atribución a la ENAC de la función de acreditar los laboratorios a los que se encomienda la calibración de los SAM de las emisiones contaminantes a la atmósfera, a través de un ensayo NGC2, que se contiene en la norma impugnada, se encuadra en la competencia estatal en materia industrial, amparada por el art. 149.1.13 CE y, por ello, no se invaden las competencias ejecutivas autonómicas en materia de medio ambiente de la Generalitat de Catalunya.

\subsection{Obligación de las Comunidades Autónomas de elaborar planes para la protección de la atmósfera}

La STS 1950/2020, de 22 de junio, establece literalmente: «Dicho de otro modo, la propia legislación básica impone a las distintas Administraciones públicas el deber de llevar a cabo las correspondientes actuaciones, incluidos los planes y programas para la protección de la atmósfera, en el ámbito de sus competencias, cuando se den las circunstancias legalmente establecidas al efecto, de cuyo cumplimiento responden en tal medida cada una con independencia de la actuación de las demás, sin perjuicio de que en su elaboración se atienda a los principios de cooperación y colaboración entre las Administraciones».

Sobre esta materia, téngase en cuenta J. PONCE SOLÉ, «Una histórica sentencia del Tribunal Supremo holandés de 20 de diciembre de 2019 obliga al Estado a reducir las emisiones de gases invernadero en un 20 por 100 a partir de 2020: lecciones para el caso español: calentamiento global y derecho a una buena administración», La Administración al día (INAP), 10 de enero de 2020, pp. 1-5.

\section{Residuos}

\subsection{Competencias municipales en materia de residuos comerciales no peligrosos}

La STS 3506/2020, de 29 de octubre, analiza el alcance de la potestad normativa de un municipio en materia de residuos comerciales no peligrosos, a la luz de lo de- 
terminado en el art. 12.5.c)2..$^{\circ}$ de la Ley 22/2011, de 28 de julio, de residuos y suelos contaminados. El Tribunal Supremo establece que dicho precepto debe interpretarse en el sentido de que, «establecido por el ayuntamiento en su ordenanza municipal de residuos, el servicio de gestión de residuos, en base a criterios de mayor eficiencia y economía suficientemente acreditados, puede imponerse la incorporación obligatoria a este servicio de gestión de residuos a todos los supuestos de productores en dicho ámbito municipal. Es decir, "en determinados supuestos" puede ser determinado como extensivo, tras los informes municipales apreciados, a todos los supuestos de productores de residuos». Por tanto, a la vista de esta interpretación, es perfectamente posible que un municipio, a través de su Ordenanza de residuos, incorpore, como hizo el Ayuntamiento de Calvià en la suya, la obligación de que todos los productores de residuos comerciales no peligrosos y de residuos domésticos generados por las industrias canalicen la recogida por medio del servicio municipal, impidiendo así la posibilidad de que los productores gestionen por sí mismos la recogida. Eso sí, será preciso que esa obligación se imponga de forma motivada y esté justificada en criterios de mayor eficiencia y economía acreditados, tal y como había sucedido en el caso objeto de análisis.

En esta materia también hay que traer la STSJ de Madrid 180/2020, de 6 de febrero, en la que se vuelve a afirmar que un ayuntamiento para que tenga competencias en materia de residuos comerciales tiene que haber asumido la competencia de gestión de este tipo de residuos. Solo en este caso cabe que pueda ejercer la potestad sancionadora en esta materia. Pero lo que no puede hacer un ayuntamiento es arrogarse esta competencia cuando contesta a una demanda dentro de un proceso judicial. Ello no significa que carezca de potestades sancionatorias o competencias ambientales; si bien deben ejercerlas con arreglo al principio de legalidad.

\subsection{Valorización de residuos}

La STJUE de 28 de mayo de 2020, asunto C-654/18, resuelve una cuestión prejudicial planteada con respecto al Reglamento (CE) 1013/2006, relativo a los traslados de residuos (art. 3.2), y aborda cuestiones importantes sobre el traslado de residuos, como, por ejemplo, el concepto de "valorización ambientalmente racional», que figura en el Reglamento 1013/2006 (Anexo III) pero no se define y pone de manifiesto las posibles divergencias entre Estados miembros a la hora de clasificar las mezclas de residuos. El Tribunal de Justicia reconoce un amplio margen de apreciación a los Estados para adoptar criterios sobre la presencia de impurezas en las mezclas, mientras no existan normas comunes, aunque recuerda que el procedimiento del art. 18 (requisitos de información general), más flexible, debe interpretarse en sentido estricto, pues constituye una excepción al procedimiento general del art. 3.1 del Reglamento (notificación y autorización previas). 


\subsection{Economía circular. Concepto de residuo y subproducto, relación con los lodos de EDAR}

La STJUE (Sala 2.a), de 14 de octubre de 2020, asunto C-629/19, por la que se resuelve una cuestión prejudicial relacionada con la interpretación de la Directiva 2008/98/CE, sobre los residuos, se centra en determinar el concepto de residuo o subproducto en relación con los lodos de EDAR, ya provengan de la depuración de aguas residuales urbanas o industriales. En este caso, los lodos de EDAR, dado que se destinan a valorización energética y no agraria, están sujetos a la normativa de residuos.

La cuestión se centra en si tales lodos deben ser considerados residuos (lo que exigiría autorización de gestor) o si son subproductos cuando se valorizan energéticamente, es decir tal operación no implica transformación alguna del residuo y además se obtiene un rédito económico de los mismos con lo que su poseedor no tiene una simple intención de desprenderse. Lo que determina el TJUE es que tales lodos no serán considerados residuos si antes de ser valorizados energéticamente cumplen las condiciones del 6.1 de la Directiva, esto es, que además de no requerir transformación previa, sobre todo que no superen los valores legales límite para las sustancias contaminantes. Es decir que su incineración no tenga impactos adversos globales para el medio ambiente o la salud y que ese proceso presente una ventaja significativa para el medio ambiente como consecuencia de la utilización de materiales resultantes de la valorización en favor de la preservación de los recursos naturales y de la creación de una economía circular.

Sobre esta materia, téngase en cuenta: C. DEL POzO, «Alcance y efectos de la figura del "Fin de la condición de residuo" del artículo 6 de la Directiva Marco de Residuos", en M. Á. Recuerda Girela (dir.), Anuario de Derecho Administrativo 2020, Cizur Menor (Navarra), Aranzadi Thomson Reuters, 2020, pp. 641-660.

\subsection{Clausura de vertedero. Acondicionamiento}

La STJUE de 14 de mayo de 2020, asunto C-15/19, aclara aspectos esenciales derivados de la obligación que impone la Directiva 1999/31 de mantener los vertederos durante treinta años tras la clausura y su aplicación a los vertederos en funcionamiento. Destaca la interpretación del art. 10 a la luz del principio "quien contamina, paga» determinando que los costes de mantener y acondicionar el emplazamiento tras la clausura deben afrontarlos los poseedores que depositan los residuos para su eliminación y no la empresa que lo gestiona. 


\section{Ruido}

\subsection{Requisitos que deben de cumplir las mediciones acústicas}

La STSJ de Madrid 271/2020, de 6 de febrero, examina el recurso formulado por una comunidad de propietarios frente al Acuerdo del Pleno del Ayuntamiento de Madrid, de 28 de junio de 2017, por el que se declara Zona de Protección Acústica Especial el Barrio de Gaztambide, y se aprueba su Plan Zonal Específico, así como el establecimiento de los objetivos de calidad acústica perseguidos [los correspondientes al área acústica tipo $a$ ), sectores del territorio con predominio de suelo residencial]. El Tribunal se centra en determinar si la campaña de mediciones llevada a cabo por el Ayuntamiento de Madrid, entre el 6 de mayo y 8 de junio de 2015, es conforme o no con la normativa reguladora de la correspondiente metodología de trabajo. En este caso, «no consta que la concreta campaña de mediciones hubiese sido precedida por una evaluación preliminar mediante mediciones en continuo durante al menos veinticuatro horas, correspondientes a los episodios acústicamente más significativos, cuyo objeto es determinar el número de puntos necesarios para la caracterización acústica de la zona» (punto 3.4.1 del Anexo IV del Real Decreto 1367/2007, de 19 de octubre). En consecuencia, el Tribunal impone al Ayuntamiento que realice una nueva campaña de mediciones en la zona con los medios adecuados.

\subsection{Contaminación acústica: medidas que deben adoptar los municipios además de la imposición de sanciones}

La STSJ de Andalucía (Granada), de 31 de enero de 2020, se centra en determinar si, además de la imposición de la multa, se debieron adoptar algunas de las medidas correctoras que autoriza la normativa de aplicación, dado que, en este caso, la potestad sancionadora no ha cumplido con su finalidad por cuanto ha impedido la conciliación entre la actividad hostelera y el descanso de los vecinos. La imposición de una multa ha resultado a todas luces insuficiente y, por tanto, resulta exigible la aplicación otras medidas correctoras como la reducción de horario de apertura de la terraza.

Sobre esta materia téngase en cuenta: M. ${ }^{a}$ C. HeRnÁNDEZ GonZÁlez, «Inviolabilidad del domicilio y contaminación acústica: novedosa interpretación del Tribunal Europeo de Derechos Humanos», en Á. VAlEnCIA SaIZ (dir.); G. SÁnCHEZ-ArChidona Hidalgo y A. M. a PAstor GarCía (coords.), Desafíos actuales del derecho: aportaciones presentadas al II Congreso Nacional de jóvenes investigadores en Ciencias Jurídicas. Málaga, EUMED, 2020, pp. 997-1010. 


\section{Contaminación visual. Infraestructuras de telefonía móvil}

La STS 4194/2020, de 10 de diciembre, analiza, a propósito de la aprobación de la Ordenanza de publicidad exterior de Ibiza, la competencia del ayuntamiento para regular sobre la contaminación visual derivada de la autorización de vallas publicitarias, sea en dominio público, sea en dominio privado, que es cuestionada por la recurrente en la medida en que considera que se trata de un concepto no regulado por la normativa estatal o autonómica. En esta sentencia el Alto Tribunal vuelve a entender que los municipios pueden establecer normas más estrictas que las del Estado y las Comunidades Autónomas cuando de la protección del medio ambiente se trata y, específicamente, de la protección del paisaje urbano, en relación con la contaminación lumínica y visual, admitiendo que en esta materia la Ordenanza municipal pueda establecer un catálogo de infracciones y sanciones. Se trata de una sentencia que avanza en la protección del paisaje urbano a partir de un concepto amplio de contaminación, que permite a los municipios poder actuar frente a distorsiones visuales producidas por las vallas publicitarias. 